\title{
Development of Athletic Training Learning Over Time Instruments
}

W. David Carr, PhD, ATC and Jennifer L. Volberding, MS, ATC • The University of Kansas

Since the phrase "Learning Over Time" (LOT) was first introduced, it has caused considerable confusion among the faculty of Athletic Training Education Programs (ATEPs). ${ }^{1}$ This confusion extends beyond the definition of the concept, because the documentation of LOT presents a difficult challenge.

Feinman-Nesmer ${ }^{2}$ addressed LOT in the context of professional teacher preparation, integration, and pro-

\section{KEY POINTS}

A set of instruments for documenting $\mathrm{LOT}$

has been developed.

Programs can adapt these instruments to their specific needs. fessional development. She presented the concept as an integration of knowledge into professional practice, but she did not discuss documentation of LOT. Letus, Moessner, and Dooley ${ }^{3}$ discussed LOT in the context of using portfolios to document learning that cannot be documented through traditional grades and exams. They felt that it is important for a student to reflect upon his or her education over time to assimilate and apply what has been learned. Konin, Amato, and Brader ${ }^{5}$ addressed LOT as an extension of a previously proposed concept of mastery over time. ${ }^{6}$ They presented the LOT concept as a sequential and progressive process of knowledge acquisition that extends from classroom instruction to clinical practice. They advocated the use of multiple sources of information to document LOT.
We have developed instruments that can be used to document LOT as a student progresses through an ATEP. The intent was to develop instruments that would be applicable to almost any injury or illness. The instruments are designed to document integration of knowledge and skills from several different content areas, synthesis of information, and critical thinking that is associated with injury or illness assessment and development of a treatment plan. In a previous report, ${ }^{4}$ we presented a case study that utilized these instruments for documentation of LOT. This report presents the results of a reliability study for our LOT instruments.

\section{Instrument Validity}

Three instruments were developed to measure and document LOT (Figure 1). Face validity was established by three athletic training educators who had 30 years of combined teaching experience and terminal degrees in higher education/ pedagogy. ${ }^{4}$ The instruments were developed for three content area courses (Care and Prevention of Injuries, Injury/Illness Evaluation, and Therapeutic Modalities). The most common components of each content area were identified. The components chosen for the Care and Prevention instrument were (a) assessment, (b) immediate care options, (c) return to play considerations, (d) demonstration of the immediate care intervention, and (e) demonstration of the return-to-play intervention. 


\section{Injury Assessment}

Name

Date

Body Part being evaluated

Definitions:

Skill - ability to perform the component with expertise, judgment, and knowledge

Efficiency - ability to perform the component with a minimum of effort or waste

Scores:

1 - not proficient, needs work

3 - proficient, adequate

5 - very proficient, excellent

(write-in 2 or 4 when needed)

History

\begin{tabular}{|ccc|ccc|}
\hline & Skill & \multicolumn{3}{|c|}{ Efficiency } \\
\hline 1 & 3 & 5 & 1 & 3 & 5 \\
\hline
\end{tabular}

Comments:

Observation/Inspection

\begin{tabular}{|ccc|ccc|}
\hline \multicolumn{3}{|c|}{ Skill } & \multicolumn{3}{|c|}{ Efficiency } \\
\hline 1 & 3 & 5 & 1 & 3 & 5 \\
\hline
\end{tabular}

Comments:

Palpation

\begin{tabular}{|ccc|ccc|}
\hline & Skill & \multicolumn{3}{|c|}{ Efficiency } \\
\hline 1 & 3 & 5 & 1 & 3 & 5 \\
\hline
\end{tabular}

Comments:

Functional Tests

\begin{tabular}{|c|c|c|c|c|c|}
\hline \multicolumn{3}{|c|}{ Skill } & \multicolumn{3}{|c|}{ Efficiency } \\
\hline 1 & 3 & 5 & 1 & 3 & 5 \\
\hline
\end{tabular}

Comments:

Overall comments/suggestions:

ACI signature

Figure l Content area instruments.
Special/Ligamentous Tests

\begin{tabular}{|ccc|ccc|}
\hline \multicolumn{3}{|c|}{ Skill } & \multicolumn{3}{|c|}{ Efficiency } \\
\hline 1 & 3 & 5 & 1 & 3 & 5 \\
\hline
\end{tabular}

Comments:

Neurovascular

\begin{tabular}{|ccc|ccc|}
\hline \multicolumn{3}{|c|}{ Skill } & \multicolumn{3}{|c|}{ Efficiency } \\
\hline 1 & 3 & 5 & 1 & 3 & 5 \\
\hline
\end{tabular}

Comments:

Assessment - Reports Their Findings to the Athlete

\begin{tabular}{|ccc|ccc|}
\hline & Skill & \multicolumn{3}{|c|}{ Efficiency } \\
\hline 1 & 3 & 5 & 1 & 3 & 5 \\
\hline
\end{tabular}

Comments 


\section{Preventative Injury Care}

Name

Date

Immediate intervention utilized

Return-to-play intervention utilized

Definitions:

Skill - ability to perform the component with expertise, judgment, and knowledge

Efficiency - ability to perform the component with a minimum of effort or waste Scores:

1 - not proficient, needs work

3 - proficient, adequate

5 - very proficient, excellent (write-in 2 or 4 if needed)

\section{Assessment of Problem/Situation}

\begin{tabular}{|ccc|ccc|}
\hline \multicolumn{2}{|c|}{ Skill } & \multicolumn{3}{|c|}{ Efficiency } \\
\hline 1 & 3 & 5 & 1 & 3 & 5 \\
\hline
\end{tabular}

Comments:

Decides Upon and Discusses an Immediate Intervention

\begin{tabular}{|ccc|ccc|}
\hline \multicolumn{3}{|c|}{ Skill } & \multicolumn{3}{|c|}{ Efficiency } \\
\hline 1 & 3 & 5 & 1 & 3 & 5 \\
\hline
\end{tabular}

Comments:

Decides Upon and Discusses a Return-to-Play Intervention

\begin{tabular}{|ccc|ccc|}
\hline & Skill & \multicolumn{3}{|c|}{ Efficiency } \\
\hline 1 & 3 & 5 & 1 & 3 & 5 \\
\hline
\end{tabular}

Comments:

Demonstrate Immediate Intervention

\begin{tabular}{|ccc|ccc|}
\hline & Skill & \multicolumn{3}{c|}{ Efficiency } \\
\hline 1 & 3 & 5 & 1 & 3 & 5 \\
\hline
\end{tabular}

Comments:

Demonstrate Return-to-Play Intervention

\begin{tabular}{|ccc|ccc|}
\hline & Skill & \multicolumn{3}{|c|}{ Efficiency } \\
\hline 1 & 3 & 5 & 1 & 3 & 5 \\
\hline
\end{tabular}

Comments:

Overall comments/suggestions:

ACI signature

Student signature

Figure l (continued) 


\section{Therapeutic Modalities}

Name

Date

Modality being utilized

Definitions:

Skill - ability to perform the component with expertise, judgment, and knowledge

Efficiency - ability to perform the component with a minimum of effort or waste Scores:

1 - not proficient, needs work

3 - proficient, adequate

5 - very proficient, excellent

(write-in 2 or 4 if needed)

Discusses Indications/Contraindications

\begin{tabular}{|ccc|ccc|}
\hline \multicolumn{3}{|c|}{ Skill } & \multicolumn{3}{|c|}{ Efficiency } \\
\hline 1 & 3 & 5 & 1 & 3 & 5 \\
\hline
\end{tabular}

Comments:

Equipment

\begin{tabular}{|ccc|ccc|}
\hline \multicolumn{3}{|c|}{ Skill } & \multicolumn{3}{c|}{ Efficiency } \\
\hline 1 & 3 & 5 & 1 & 3 & 5 \\
\hline
\end{tabular}

Comments:

Preparation and Treatment

\begin{tabular}{|ccc|ccc|}
\hline & Skill & \multicolumn{3}{|c|}{ Efficiency } \\
\hline 1 & 3 & 5 & 1 & 3 & 5 \\
\hline
\end{tabular}

Comments:

Ending Treatment

\begin{tabular}{|ccc|ccc|}
\hline & Skill & \multicolumn{3}{|c|}{ Efficiency } \\
\hline 1 & 3 & 5 & 1 & 3 & 5 \\
\hline
\end{tabular}

Comments:

Overall comments/suggestions:

ACI signature

Student signature

Figure I (continued)

The components chosen for the Injury Assessment instrument were (a) acquisition of history, (b) observation/inspection for signs of trauma, (c) palpation for areas of tenderness, (d) range of motion assessments, (e) performance of special tests, (f) performance of a neurovascular assessment, and (g) development of a conclusion. The components chosen for the Therapeutic Modalities instrument were (a) discussion of indications/contraindications, (b) set-up of the equipment, (c) demonstration of treatment administration, and $(d)$ termination of treatment. 


\section{Reliability Assessment}

Subjects were recruited from the undergraduate Athletic Training program of a large Division I university. Informed consent was obtained from each subject before data collection proceeded. Ten students from the senior class ( 5 females and 5 males, 21 to 24 years of age) were used as subjects.

To establish the reliability of each instrument, athletic training students were individually presented with a simulated patient who exhibited a predetermined injury. The simulated patient exhibited one of three common lower extremity injuries (inversion ankle sprain, Achilles tendonitis, or a Jones fracture). The students were required to assess the injury, discuss and apply preventative care techniques, and discuss and apply therapeutic modalities. Two athletic training educators, who had 15 years of combined teaching experience, observed and independently rated each component of the three content areas for both skill and efficiency: 1 = not proficient/needs work; $3=$ proficient/adequate; and $5=$ very proficient/excellent. Both evaluators had previous experience with the three instruments. Skill was defined as the ability to perform the component with expertise, judgment, and knowledge. Efficiency was defined as the ability to perform the component with minimal waste of effort or resources.

The Pearson correlation coefficient was calculated to represent agreement between the two evaluators. Skill and efficiency means and standard deviations were calculated for each of the three separate instruments and for the three instruments collectively. SPSS 16.0 and Microsoft Excel were used to perform all calculations, which are presented in Table 1. Correlation coefficients between .30 and .60 were found for two-thirds (21 of 32 ) of the skill and efficiency ratings.

TABLE 1. CORRELATION RESULTS FOR EACH TASK, MEAN (SD) CORRELATION RESULTS FOR EACH CONTENT AREA, AND MEAN (SD) CORRELATION RESULTS FOR SKILL AND EFFICIENCY

\begin{tabular}{|lcc|}
\hline Content Area & & Correlation \\
\hline General Task & Component & .583 \\
\hline Injury Assessment & Skill & .574 \\
\hline History & Efficiency & $.661^{* *}$ \\
\hline Observation/Inspection & Skill & $.752^{* *}$ \\
& Efficiency & .055 \\
\hline Palpation & Skill & .491 \\
\hline Functional tests & Efficiency & $.744^{* *}$ \\
\hline Special tests & Skill & .604 \\
& Efficiency & -.122 \\
\hline Neurovascular & Skill & $.722^{* *}$ \\
& Efficiency & $.638^{* *}$ \\
\hline Assessment/Diagnosis & Skill & $.791^{*}$ \\
\hline Mean (SD) for Injury Assessment & Efficiency & .090 \\
Mean (SD) for Injury Assessment & Skill & .238 \\
\hline
\end{tabular}




\begin{tabular}{|c|c|c|}
\hline \multicolumn{3}{|l|}{ Content Area } \\
\hline General Task & Component & Correlation \\
\hline \multicolumn{3}{|l|}{ Preventative Injury Care } \\
\hline \multirow[t]{2}{*}{ Assessment of injury } & Skill & .323 \\
\hline & Efficiency & .352 \\
\hline \multirow[t]{2}{*}{ Discuss immediate care } & Skill & .087 \\
\hline & Efficiency & .073 \\
\hline \multirow[t]{2}{*}{ Discuss return to play } & Skill & .325 \\
\hline & Efficiency & .164 \\
\hline \multirow[t]{2}{*}{ Demonstrate immediate care } & Skill & $.698^{* *}$ \\
\hline & Efficiency & $.802^{* *}$ \\
\hline \multirow[t]{2}{*}{ Demonstrate return to play } & Skill & .549 \\
\hline & Efficiency & $.729^{* *}$ \\
\hline Mean (SD) for Preventative Injury Care & Skill & $.396(.23)$ \\
\hline Mean (SD) for Preventative Injury Care & Efficiency & $.424(.32)$ \\
\hline \multicolumn{3}{|l|}{ Therapeutic Modalities } \\
\hline \multirow[t]{2}{*}{ Discuss indications } & Skill & .238 \\
\hline & Efficiency & .577 \\
\hline \multirow[t]{2}{*}{ Equipment set-up } & Skill & .479 \\
\hline & Efficiency & $.659 * *$ \\
\hline \multirow[t]{2}{*}{ Preparation and Treatment } & Skill & .104 \\
\hline & Efficiency & 0.0 \\
\hline \multirow[t]{2}{*}{ End treatment } & Skill & $.687^{* *}$ \\
\hline & Efficiency & $.739 * *$ \\
\hline Mean (SD) for Therapeutic Modalities & Skill & $.377(.25)$ \\
\hline \multirow[t]{3}{*}{ Mean (SD) for Therapeutic Modalities } & Efficiency & $.493(.33)$ \\
\hline & Mean (SD) for Skill & $.383(.28)$ \\
\hline & Mean (SD) for Efficiency & $.517(.26)$ \\
\hline
\end{tabular}

Abbreviation: (SD) Standard Deviation

$* p<.001$

$* * p<.05$

\section{Discussion}

We interpret our results to suggest that the LOT instruments have an acceptable level of reliability for ratings of both skill and efficiency in each content area. The Care and Prevention instrument demonstrated the highest correlation values, which may have been due to our curriculum sequence. The .09 correlation for the skill component of the assessment/diagnosis task of the Injury Assessment instrument is troubling. If the evaluators cannot agree that a student is properly applying skills to establish a correct assessment/diagnosis, the student may not be receiving constructive feedback during the process of learning the skill. Letus, 
Moessner, and Dooley ${ }^{3}$ discussed the LOT concept in the context of using portfolios to document learning that cannot be documented through grades and exams. The authors described how portfolios allow students to reflect upon educational experiences over time and to determine what the learning process means to them personally and professionally. A qualitative approach to LOT is important to consider. Our LOT evaluation plan includes self-reflection by the student following skill demonstration.

Kell and van Deursen ${ }^{7}$ discussed the LOT concept in the context of learning preferences and self-directed learning of adult students. Clinical practice requires the use of problem-solving skills and critical thinking, which are central to the application of the LOT concept to athletic training education.

Further assessment of the psychometric properties of the instruments should utilize a much larger sample of students who have attained differing levels of clinical skill. Development of a scoring rubric that clearly defines the meaning of each level of the 5-point scale may enhance the reliability of the instruments.

\section{Summary}

Our approach to documentation of LOT could be used to assess almost any psychomotor skill. Every athletic training educator should promote the development of problem solving and critical thinking skills, which are not acquired quickly. Documentation of LOT is important to ensure that each student acquires the necessary knowledge and skills during progression through an ATEP to ultimately become a clinician who provides high-quality patient care.

\section{References}

1. Commission on Accreditation of Allied Health Education Programs. 2001 Joint Review Committee - Athletic Training Standards for Accreditation

2. Feiman-Nesmer S. From preparation to practice: designing a continuum to strengthen and sustain teaching. Teach Coll Rec. 2001;103(6):1013-55.

3. Letus M, Harmon-Moessner P, Dooley L. The clinical portfolio as an assessment tool. Nurs Admin Quart. 2001;25(1):74-9.

4. Carr W, Ploeger R, Drummond J. Learning over time literature review and documentation case report. Athl Ther Today. 2007;12(5):20-25.

5. Konin J, Amato H, Brader H. Incorporating the Renne test into the learning-over-time model. Athl Ther Today. 2002; 7(5):12-7.

6. Amato H, Gebauer C, Brader H. (2001). Clinical competencies: mastery over time. In Proceeding from the 2001 NATA Athletic Training Educators' Conference. Fort Worth, TX. January 19-21, 2001. Champaign, IL: Human Kinetics.

7. Kell C, van Deursen R. Student learning preferences reflect curricular change. Med Teacher. 2002;24(1):32-40.

W. David Carr is assistant professor and Athletic Training Program Director at the University of Kansas in Lawrence.

Jennifer Volberding is with the Health, Sports, and Exercise Sciences Department at the University of Kansas in Lawrence. 
Copyright of Athletic Therapy Today is the property of Human Kinetics Publishers, Inc. and its content may not be copied or emailed to multiple sites or posted to a listserv without the copyright holder's express written permission. However, users may print, download, or email articles for individual use. 